\title{
In Vitro Selection of Calli for Salt Tolerance in Tomato (Solanum lycopersicum L.)
}

\author{
A. Biswas, Md. R. Islam., MRU Rashed, N. Zeba
}

Department of Genetics and Plant Breeding, Sher-e-Bangla Agricultural University, Dhaka, Bangladesh

\begin{abstract}
Soil salinity is one of the most important abiotic stresses that limit crop production. Responses of six breeding lines (BD-7755, BD-7757, BD-9008, BD-9011, $B D-10122, B D-10123$ which were named as G1, G2, G3, $G 4, G 5$ and $G 6$ respectively) of tomato (Solanum lycopersicum L) to $\mathrm{NaCl}$ stress were studied in callus induction. Hypocotyl and cotyledon segments were chosen as explants for callus induction in vitro. The six investigated tomato genotypes differed in their callus growth. Tomato seeds were cultured for callus formation and that callus were treated with $0 \mathrm{mM}$ (control), $50 \mathrm{mM}, 100 \mathrm{mM}, 150$ $\mathrm{mM}$ and $200 \mathrm{mM} \mathrm{NaCl}$ in nutrient solutions. The effect of the stress applied on the callus was evaluated in 10 DAT (Days After Treatment) and 17 DAT. Different concentrations of $\mathrm{NaCl}$ in the medium significantly affected the biomass callus size and callus weight of tomato. G2 and G6 showed excellent performance of tolerance up to $50 \mathrm{mM}$ of $\mathrm{NaCl}$. G6 showed better performance under high salt concentrations i.e., at $100 \mathrm{mM}$ and $200 \mathrm{mM}$ but not at low salt stress. It indicates the expression of functional gene occurs at high salt stress. However it is possible to select callus line tolerant to elevated levels of $\mathrm{NaCl}$ stress by sudden exposure to high of $\mathrm{NaCl}$, accordingly a $\mathrm{NaCl}$ tolerant cell line was selected from hypocotyls and cotyledon derived callus of tomato which proved to be a true cell line variant. The interaction effect of variety and treatmentrevealed that genotype G6 and G1 were the highest and lowest performer respectively. These findings indicated some salt tolerant tomato genotypes which will be promising for regeneration and for future breeding program. It is quiet necessary to asses accumulation of proline and the anti-oxidant enzymes like Super Oxide Dismutase, Ascorbate Peroxidase and Catalase from the control and stressed callus as they are the indicator of salt tolerance. It is evident that tissue culture technique was able to evaluate several genotypes for salt tolerance into cell level under controlled environment with relatively little space and less time required comparing with such process studies at the whole plant level.
\end{abstract}

Keywords - In vitro, Salt tolerance, Tomato.

\section{INTRODUCTION}

Tomato (Solanum lycopersicum L.) is one of the most important solanaceous vegetable crops in the world in terms of both production and harvested area. Though it is a selfcrossing annual crop, nowadays, tomatoes are grown round the year. Due to increasing consumption of tomato products, the crop is becoming promising. In Bangladesh, the yield of tomato is not enough satisfactory in comparison to the other tomato growing countries of the World (Aditya et al., 1999). The low yield of tomato in Bangladesh however is not an indication of low yielding potentially of this crop but of the fact that the low yield may be attributed to a number of reasons, viz. unavailability of quality seeds of high yielding varieties, land for production based on light availability, fertilizer management, pest infestation as well as production in abiotic stress conditions especially high salinity.

Salinity is one of the major stress factors among the abiotic stresses. In the world, about 400 million hectares of land are affected by high salinity. In Bangladesh about 1 million hectares of land are affected by high salinity in the coastal regions and it is increasing day by day. Salinity affects almost every aspect of the morphology, physiology and biochemistry of plants and significantly reduces yield (Aazami et al., 2010; Amini and Ehsanpour, 2006; Zhang et al., 2004). As saline soils and saline waters are common around the world, great effort has been devoted to understanding physiological aspects of tolerance to salinity in plants, as a basis for plant breeders to develop salinitytolerant genotypes. In spite of this great effort, only a small number of cultivars, partially tolerant to salinity, have been developed. Further effort is necessary if the exploitation of saline soils and saline waters that are not currently usable is to be achieved. Salinity affects yield and quality, so that yield characters must be taken into account when breeding for salinity tolerance. But not only yield-related characters are important. As salinity affects almost every aspect of the physiology and biochemistry of the plant, the enhancement of crop salt tolerance will require the combination of several too many physiological traits (Cuartero et al., 2006; 
Cuartero and Ferna'ndez-Muñoz, 1999; Flowers and Yeo, 1995), not simply those directly influencing yield. As salinity in soils is variable and plant tolerance depends on the stage of plant development, plants should be phenotyped at several salinity concentrations and at the most sensitive plant stage(s).

As salinity is a major factor in limiting crop productivity in semi-arid areas of the world, the selection of salt tolerance lines continues to challenge plant scientists, especially those working in physiology and genetics. If it is possible to use cell and tissue culture techniques, together with conventional breeding and genetic engineering (Mohamed et al., 2011; Shatnawi, 2006; Cano et al., 1998), for the development of plants with increased tolerance to salt stress, the major problem in selecting salt tolerant lines could be the difficulty of screening thousands of plants without a reliable selection for criterion. In vitro culture, besides its use as a tool for obtaining salt tolerant plants, may offer potential for quick evaluation of germplasm against salt stress. In vitro techniques make it possible to screen the required number of genotypes rapidly since in vitro plant exhibit their capacity to withstand the stress (Tewary et al., 2000). In many species like tobacco, grape, rice citrus and carrot salt tolerant lines have been isolated using in vitro techniques (Vijayan et al., 2003; Tewary et al., 2000; Ben-Hayyim, 1987).

Tomato is sensitive to moderate levels of salt in the soil. Tomato genotypes' response to salinity is genetic and species dependant and there is too much interest in screening and breeding for higher salt tolerance (Mohamed et al., 2007; Amini and Ehsanpour, 2006). Tomato is also a favorable food crop for in vitro and genetic studies due to its low chromosome no i.e., $2 n=2 x=24$ and due to comprehensive knowledge of tomato genetics. A considerable improvement has already been made by exploiting the natural variation through conventional breeding in tomato. Even though the success made in the last century, traditional breeding efforts alone cannot meet the increasing demand of tomato consumers in the $21 \mathrm{st}$ century. Therefore, plant cell and tissue culture techniques are being used for the genetic improvement and developing salt tolerant lines of tomato plant throughout the world. Several in vitro investigations have been conducted on tomato in different applications. In tomato, a positive correlation between growth of calluses and whole plants has been observed under saline condition (Tal et al., 1978; Perez-Alfocea et al., 1994). The genetics of physiological characters together with other tolerance components related to metabolic defenses against salinity have to be studied in order to advance the breeding of tomato genotypes tolerant to salinity.

This study was conducted to explore the bioassay so as to establish a reproducible protocol for selecting of different salt tolerant callus lines in tomato in different concentrations of $\mathrm{NaCl}$. With conceiving the above scheme in mind, the present research work has been undertaken in order to fulfill the following objectives:

1. To study the in vitro biomass changing of callus under different concentration of $\mathrm{NaCl}$.

2. To investigate the callus induction ability of six genotypes of tomato under different $\mathrm{NaCl}$ concentrations.

3. To identify and select the salt tolerant callus lines.

4. To find out the effect of $\mathrm{NaCl}$ at varied levels on biomass character of six tomato genotypes by using hypocotyls and cotyledons explants.

5. To establish an effective callus induction protocol for six genotypes of tomato under control and salt stress condition.

6. To develop of somaclonal variant from the salt tolerant calli.

7. To assay the magnitude of genetic divergence in tomato genotypes regarding callus induction.

\section{MATERIALS AND METHODS}

The study was conducted at the Genetics and Plant Breeding Laboratory of Sher-e Bangla Agricultural University, Dhaka, Bangladesh during the period from March, 2013 to June, 2014 to study the in vitro selection of salt tolerant callus lines in Tomato. The experiment was done in different steps:

1. In vitro seed germination of different genotypes.

2. In vitro callus initiation and sub-culturing of callus.

3. In vitro salt treatment of different concentration (0Mm, 50Mm, 100Mm, 150Mm and $200 \mathrm{Mm}$ ) in six genotypes.

The materials and methods of this experiment are presented in this chapter under the following headings -

\section{Experimental site}

The experiment was carried out at the Genetics and Plant Breeding Laboratory, Sher-e-Bangla Agricultural University, Dhaka during the period of March, 2013 to September, 2014. The place is geographically located at about $24^{\circ} 75^{\prime}$ North latitude and $90^{\circ} 50^{\prime}$ East longitude.

\section{Experimental material \\ Plant materials}


A total of six genotypes of tomato originated from different places of Bangladesh were used in this experiment. The materials were collected from Plant Genetic Resource
Centre (PGRC) at Bangladesh Agricultural Research Institute (BARI), Gazipur. The name and origin of these genotypes are presented in Table 1.

Table.1: List of the tomato genotypes used in the experiment

\begin{tabular}{|c|c|c|c|}
\hline SL. No. & Genotypes No. & Name/Acc No. (BD) & Origin \\
\hline 01 & G1 & BD-7755 & PGRC, BARI \\
\hline 02 & G2 & BD-7757 & PGRC, BARI \\
\hline 03 & G3 & BD-9008 & PGRC, BARI \\
\hline 04 & G4 & BD-9011 & PGRC, BARI \\
\hline 05 & G5 & BD-10122 & PGRC, BARI \\
\hline 06 & G6 & BD-10123 & PGRC, BARI \\
\hline
\end{tabular}

PGRC=Plant Genetic Research Centre, BARI=Bangladesh Agricultural Research Institute

\section{Laboratory materials}

Laboratory preparation was started in early March 2013 by collecting chemical and instruments.

\section{Chemicals}

MS medium, Sterilizing chemicals (Sodium hypo chlorite $\mathrm{NaOCl}, 70 \%$ ethanol), Sucrose, Agar, $\mathrm{NaOH}(10 \mathrm{~N}, 1 \mathrm{~N})$, $\mathrm{HCl}, \mathrm{KCl}(3 \mathrm{M}), \mathrm{NaCl}$ (laboratory grade), Absolute Ethanol, Ethanol (70\%), Methilated spirit, NAA (1Naphthaleneacetic acid ), BAP (6-Benzylaminopurine).

\section{Instruments}

Autoclave, Hotplate with magnetic stirrer, Automatic drying oven, Freezers, Furnaces, Incubators,Laminar Air Flow Chamber, Microwave oven, Pipettes, Plant Growth Chamber, Safety Cabinets, Shakers, Shaking Incubator, Water Purification System, $\mathrm{pH}$ meter, Course and fine electric balances, Scalpel, forceps, scissors etc., Culture vials (petridishes, test tubes, culture bottles).

\section{Culture media}

Success of any experiment depends on the culture media, hormone combination, tissue and employing cell. Murashige and Skoog (1962) medium were used with different hormone supplements as culture medium for callus induction. Different concentration of salt was added to the basal MS medium supplemented with auxin and cytokinine. Three types of culture media were used in this study, viz,

1. Hormone free basal MS medium for raising of seedling to get explants.

2. MS medium supplemented with $2 \mathrm{mg} / \mathrm{l}$ of BAP and $0.2 \mathrm{~g} / \mathrm{l}$ of NAA for callus induction.

3. MS medium as 2 . supplemented with different salt concentrations $(0 \mathrm{mM}, 50 \mathrm{mM}, 100 \mathrm{mM}, 150 \mathrm{mM}$ and $200 \mathrm{mM}$ ) for salt stress treatment.
Murashige and Skoog (1962) medium were used with different $\mathrm{NaCl}$ concentration as culture medium for selection of salt tolerant callus. The composition of MS medium has been presented in Appendix $1 . \mathrm{NaCl}$ were added to MS media as per treatment of the experiment. For the preparation of media, stock solutions were prepared at the beginning and stored in the refrigerator at $4 \pm 1^{\circ} \mathrm{C}$. The respective media were prepared from stock solutions.

\section{Preparation of the stock solutions}

The first step in the preparation of the medium is the preparation of stock solutions of the various constituents of the MS medium. As different media constituents were required in different concentrations, separate stock solutions for the macronutrients, micronutrients, Fe-EDTA (Iron stock), vitamins and growth regulators were prepared separately for ready use.

\section{Stock solution of macronutrients (stock 1)}

Stock solution of macronutrients was prepared with 10 times of the final strength of the medium in one liter of distilled water (DW). Ten times the weight of the salts required for one liter of medium weighted accurately. All the macronutrient were dissolved one by one except $\mathrm{CaCl}_{2}$. The stock solution of $\mathrm{CaCl}_{2}$ should be prepared separately in order to avoid precipitation. And in this way, dissolved all the salts thoroughly in $750 \mathrm{ml}$ of distilled water and final volume was made up to one liter by further addition of (distilled water) DW. The stock solution was poured into a clean sterilized glass container and stored in a refrigerator at $4^{\circ} \mathrm{C}$ for ready use.

Stock solution of micronutrients (stock 2)

A stock solution of all the micronutrients with $100 x$ concentration is generally prepared. Since copper and cobalt are required in very small quantities, it was preferable to 
first make a separate stock solution of those two salts (100X) and then an appropriate volume were pipetted and put into the main micronutrient stock solution. This stock solution was also stored in refrigerator at $4^{\circ} \mathrm{C}$.

Stock solutionof iron (Fe-EDTA) (stock 3)

Iron-EDTA should be added fresh and it was made 100 times the final strength of the medium in one liter DW. Here, two constituents, $\mathrm{FeSO}_{4} \cdot 7 \mathrm{H}_{2} \mathrm{O}$ and $\mathrm{Na}_{2}$ EDTA, were dissolved in $750 \mathrm{ml}$ of DW in a conical flask by heating in a water bath until the salts dissolved completely and final volume was made up to one liter by further addition of DW. This stock should be stored in an amber color bottle or a bottle covered with an aluminum foil and stored in refrigerator at $4^{\circ} \mathrm{C}$.

\section{Stock solution of vitamins (stock 4)}

The vitamins used in the present study for the preparation of MS medium were, Myo-inositol (Inositol), Nicotinic acid (Vitamin $\mathrm{B}_{3}$ ), Pyridoxin $\mathrm{HCl}$ (Vitamin $\mathrm{B}_{6}$ ), Thiamine $\mathrm{HCl}$ (Vitamin $B_{1}$ ) and Glycine. Each of the vitamins except myo-inositol were taken at 100 times of their final strength in measuring cylinder and dissolved in $400 \mathrm{ml}$ of distilled water. The final volume was made up to $1000 \mathrm{ml}$ by further addition of distilled water. This stock solution was also labeled and stored in a refrigerator at $4^{\circ} \mathrm{C}$.

\section{MS Media preparation}

To prepare one liter of MS medium, the following steps were followed:

1. $500 \mathrm{ml}$ double distilled water was taken into 1 liter beaker

2. 4.4gm MS mixture was added in this $500 \mathrm{ml}$ double distilled water

3. $30 \mathrm{~g}$ of sucrose was dissolved in this solution with the help of magnetic stirrer

4. $8 \mathrm{gm}$ of agar was added and finally the whole mixture was then made up to 1 liter with further addition of double distilled water.

\section{pH of the medium}

$\mathrm{pH}$ of the medium was adjusted to $5.7 \pm 1$ by $\mathrm{pH}$ meter with the addition of $1 \mathrm{~N} \mathrm{NaOH}$ or $0.1 \mathrm{~N} \mathrm{HCl}$ whichever was necessary.

\section{Agar}

The media was gelled with $8 \mathrm{~g} / \mathrm{l}$ agar and the whole mixture was gently heated on microwave oven at $250{ }^{\circ} \mathrm{C}$ Temperature for 8-10 minutes.

\section{Preparation of NAA (50X)}

A stock solution of NAA with 50x concentration was generally prepared. $0.2 \mathrm{mg}$ NAA was dissolved in few drops of $1 \mathrm{~N} \mathrm{NaOH}$. In this way, this solution was dissolved in $750 \mathrm{ml}$ of distilled water and final volume was made up to one liter by further addition of DW. The stock solution was poured into a clean sterilized glass container and stored in a refrigerator at $4^{\circ} \mathrm{C}$ for ready use.

\section{Preparation of BAP (10X)}

A stock solution of BAP with $10 \mathrm{X}$ concentration was generally prepared. $2 \mathrm{mg}$ BAP was dissolved in few drops of $1 \mathrm{~N} \mathrm{NaOH}$. This solution was dissolved in $750 \mathrm{ml}$ of distilled water and final volume was made up to one liter by further addition of DW. This stock solution was also labeled and stored in a refrigerator at $4^{\circ} \mathrm{C}$.

\section{Preparation of $1 \mathrm{~N} \mathrm{NaOH}$}

$40 \mathrm{~g} \mathrm{NaOH}$ pellets were weighed and dissolved in $900 \mathrm{ml}$. of sterilized distilled water under stirring condition. The flask in a thermostat at $20^{\circ} \mathrm{C}$ and maintain for 1 hour and volume with sterilized distilled water up to $1 \mathrm{~L}$.

\section{Preparation of $70 \%$ Ethanol}

In a $100 \mathrm{ml}$ measuring cylinder $70 \mathrm{ml} \mathrm{99.9 \%}$ ethanol was poured. Double distilled water was poured up to the level of $100 \mathrm{ml}$. The solution was stored in a sterilized glass bottle. This solution was made fresh each time before use.

\section{MS medium supplemented with $50 \mathrm{mM} \mathrm{NaCl}$}

The molecular weight of $\mathrm{NaCl}$ is 58.44 gm. For preparing MS medium supplemented with $1 \mathrm{M} \mathrm{NaCl}$ solution, we needed to add $58.44 \mathrm{~g} \mathrm{NaCl}$ in $1000 \mathrm{ml}$ of distilled water. So for preparing $50 \mathrm{mM}$ concentration, $2.92 \mathrm{~g}$ of $\mathrm{NaCl}$ was added to the MS medium.

MS medium supplemented with $100 \mathrm{mM} \mathrm{NaCl}$

For $100 \mathrm{mM}$ concentration, $5.84 \mathrm{~g}$ of $\mathrm{NaCl}$ was added to the $1 \mathrm{~L}$ of MS medium.

MS medium supplemented with $150 \mathrm{mM} \mathrm{NaCl}$

For $150 \mathrm{mM}$ concentration, $8.78 \mathrm{~g}$ of $\mathrm{NaCl}$ was added to the $1 \mathrm{~L}$ of MS medium.

MS medium supplemented with $200 \mathrm{mM} \mathrm{NaCl}$

For $200 \mathrm{mM}$ concentration, $11.68 \mathrm{~g}$ of $\mathrm{NaCl}$ was added to the $1 \mathrm{~L}$ of MS medium.

\section{Sterilization}

\section{Sterilization of culture media}

Fixed volume of medium was dispensed into conical flasks. After dispensing the flasks were covered with aluminum foil paper and marked with different codes with the help of a permanent glass marker to indicate specific hormonal 
supplement. Then flasks were autoclaved at 15 psi pressure at $121^{\circ} \mathrm{C}$ for 20 minutes. The medium was then transferred into the culture room and cooled at $24^{\circ} \mathrm{C}$ temperature before used. Marking is also necessary. Fixed volume of medium was aliquoted into petridishes under laminar hood (Plate 1). After dispensing the petridishes were covered with thin polythene (Swaran wrap) and marked with different codes with the help of a permanent glass marker to indicate specific $\mathrm{NaCl}$ supplements. The petridishes containing media could be store at $4^{0} \mathrm{C}$ until use. Marking was done for identification.

\section{Sterilization of glassware and instruments}

Glassware, culture vessels, beakers, petridishes, pipettes, slides, plastic caps, other instruments such as forceps, needles, scissor, spatula, surgical blades, brush, cotton, instrument stand and aluminum foil were sterilized in an autoclave at a temperature of $121^{\circ} \mathrm{C}$ for 20 minutes at $15 \mathrm{psi}$ pressure. Before this, all types of glassware instrument was washed properly by liquid detergent, cleaned with running tap water and finally washed with distilled water.

\section{Sterilization of culture room and transfer area}

At the beginning, the culture room was sprayed with formaldehyde and then the room was kept closed for one day. Then the room was cleaned through gently washing the floors, walls and rakes with a detergent. This was followed by careful wiping them with $70 \%$ ethanol. This process of sterilization of culture room was repeated at regular intervals. The transfer area was also cleaned with detergent and also sterilized twice in a month by $70 \%$ ethanol. Laminar air flow cabinet was usually sterilized by switching on the cabinet. The ultra violate ray kills the microbes inside the laminar airflow. It switches on 30 minutes before working in empty condition and for 20 minutes with all the instruments. The working surface was wiping with $70 \%$ ethanol, 30 minutes before starting the transfer work.

\section{Raising of seedling in vitro}

Seeds of six genotypes (Table 1) of Solanum lycopersicum L.were surface sterilized and germinated under in vitro conditions as per standard tissue culture procedure. Briefly, seeds were surface sterilized with $70 \%$ ethanol for $1 \mathrm{~min}$ followed by sodium hypochlorite, $\mathrm{NaOCl}(10 \%)$ for six minutes and then soaked with sterilized distilled water for 30 min. Seeds were inoculated in petridishes for germination in a hormone free MS (Murashige and Skoog, 1962) basal medium containing $30 \mathrm{~g}$ sucrose and $0.8 \%$ agar adjusted with pH- 5.8. Twelve seeds were inoculated per petridishes. The cultures were incubated in growth chamber under $16 \mathrm{~h} / 8 \mathrm{~h}$ light/dark photoperiod with the illuminations of white fluorescence lights $\left(50 \mu \mathrm{mol} / \mathrm{m}^{2} / \mathrm{s}^{-1}\right)$ at $25 \pm 2{ }^{\circ} \mathrm{C}$
(Plate 2). Thereafter, three weeks-old seedlings were used for explants source. All of the sterilization and inoculation steps were performed under laminar hood.

Explants preparation and inoculation

Three weeks after germination, cotyledons and hypocotyls explants were excised by aseptic manipulations. Explants of hypocotyls and cotyledons $(0.5 \mathrm{~cm})$ were isolated and inoculated in test tubes containing MS (Murashige and skoog, 1962) medium supplemented with $30 \mathrm{~g}$ sucrose, 2 $\mathrm{mg} / \mathrm{l} \mathrm{BAP}$ and $0.2 \mathrm{mg} / \mathrm{l} \mathrm{NAA}$. The $\mathrm{pH}$ of the medium was adjusted to 5.8 and solidified by $8 \mathrm{~g} / \mathrm{l}$ agar. The hypocotyls were cut into a lower, middle and upper segment. The explants were placed horizontally on the medium

surface, leaf discs explants with the adaxial surface in contact with medium. One explant was cultured in every test tube and test tubes were placed in slope condition. The cultures were incubated in normal growth room conditions (16/8 light/dark regime) having the same light intensity and temperature as above for four weeks.

\section{Callus induction and subculture}

After four weeks, the callus were induced and were the size was optimum to cut into $0.5 \mathrm{~cm}^{2}$ pieces aseptically and subcultured in fresh MS medium with the same ingredients. The calli were sub-cultured as the nutrient media were exhausted and to amplify the calli for salt treatment in different concentrations. The incubation condition was same as mentioned earlier. Within four weeks of sub-culturing, the calli became organized for different salt treatment.

\section{Salt tolerance assay}

The salt tolerance assay was performed as Zeba (2009). Briefly, Four weeks old sub-cultured callus were cut into $0.5 \mathrm{~cm}^{2}$ pieces under laminar hood and were inoculated in test tubescontaining MS medium mentioned in section 3.5 supplemented with $0 \mathrm{mM}, 50 \mathrm{mM}, 100 \mathrm{mM}, 150 \mathrm{mM}$ and $200 \mathrm{mM}$ of $\mathrm{NaCl}$. One piece of callus of each genotype was inoculated per test tube. The culture plates were kept in the growth chamber in vertical position. The culture environment included, $25 \pm 2^{\circ} \mathrm{C}, 60 \%$ relative humidity, and a 16-h photoperiod from white fluorescent lights $(200 \mu \mathrm{mol}$ photons $\left./ \mathrm{m}^{2} / \mathrm{s}^{-1}\right)$. The experiment was performed in three replications for each genotype and for each treatment.

\section{Precautions to ensure aseptic conditions}

All inoculation and aseptic manipulations were carried out under laminar air flow cabinet. The cabinet was usually switched on with ultra violet light half an hour before use and wiped with $70 \%$ ethanol to reduce the chances of contamination. The instruments like scalpels, forceps, needles, surgical blades, scissor, pipettes, slides, plastic caps, spatula, brush, cotton etc. were pre-sterilized by 
autoclaving and subsequent sterilization were done by dipping in $70 \%$ ethanol followed by flaming and cooling method inside the laminar flow cabinet. While not in use, the instruments were kept inside the laminar airflow cabinet into the instrument stand. Hands were also sterilized by $70 \%$ ethanol and wearing of hand gloves. It is also necessary to wear apron and mask to avoid contamination rate. Other required materials like distilled water, culture vessels, beakers, glass plates, petridishes etc. were sterilized in an autoclave following method of media sterilization. The neck of test tubes were flamed before open and also dipping with ethanol with the help of soaked cotton before closing it with the aluminum foil paper. Aseptic conditions were followed during each and every operation to avoid the contamination of cultures.

\section{Data recorded and statistical analysis}

Data were collected and evaluated in terms of the biomass callus weight with digital fine balance and size (diameter) using verneer caliper, after ten days and later after seventeen days of incubation. Tubes were arranged on the shelves of a controlled environment room according to a CRD (completely randomized design). Each tube had a single callus and was considered as an experimental unit. Callus response data were analyzed using MSTAT-C software. The means and the genotype environment interactions were analyzed and the test of significance was performed by DMRT (Duncan's Multiple Range Test).

\section{RESULTS AND DISCUSSION}

The experiment was carried out at the Genetics and Plant Breeding Laboratory, Sher-e-Bangla Agricultural University to study the performance of different concentrations of salton callus initiation and biomass changing of callus in terms of fresh weight and diameter of six genotypes. This study dealt with the in vitro selection of different salt tolerant callus lines in tomato. As salinity in soils is variable and plant tolerance depends on the stage of plant development, in this study, calli were phenotyped at several salinity concentrations and at the most sensitive stage (10 days old callus). The genotypes used in this study were, G1 (BD-7755), G2 (BD-7757), G3(BD-9008), G4(BD-9011), G5(BD-10122) and G6(BD-10123) and the salt concentrations were $0 \mathrm{mM}$ (T1), $50 \mathrm{mM}$ (T2), $100 \mathrm{mM}$ (T3), $150 \mathrm{mM}$ (T4) and $200 \mathrm{mM}$ (T5).

\section{Response of seedlings and callus induction}

The seeds of six genotypes were surface sterilized and inoculated in hormone free basal MS medium. The seeds started to germinate within seven days of incubation. Within three weeks of seed inoculation the length of seedlings were in appropriate size to serve as explants source for hypocotyls

and cotyledon. The hypocotyls and cotyledon segments from six tomato varieties were used as explants and cultured on MS medium supplemented with NAA and BAP. The hypocotyls and cotyledon were cut into about $0.5 \mathrm{~cm}^{2}$ size and inoculated in the test tubes. Within 3-4 days the explants became enlarge and start swelling. Within four weeks of culture the swelled explants gradually turned into green callus. For amplification and maintaining, the callus of each genotype cut into pieces aseptically and subculture in the fresh medium. The gradual change of cotyledon and hypocotyls to the callus is presented in (Plate 3). Auxin is NAA is an important media supplements for callus initiation in culture. The combined effect of different tomato varieties and hormone showed significant variation for days required to callus initiation. 


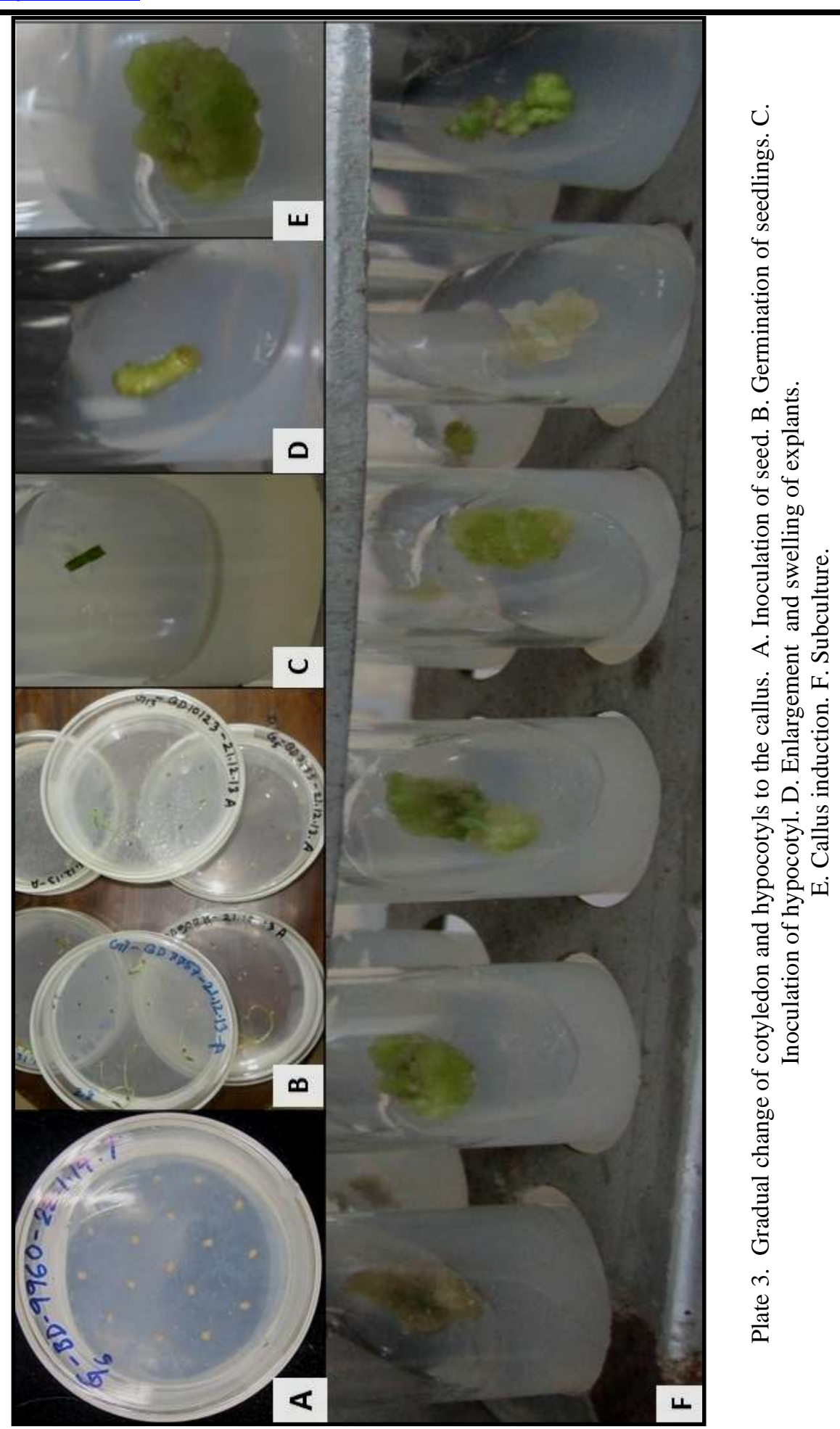

Performance of different genotypes under control and salt stress condition

To investigate the salt tolerance in six genotypes, firstly callus were grown and subcultured and then treated with different salt concentration containing $0 \mathrm{mM}, 50 \mathrm{mM}, 100$
$\mathrm{mM}, 150 \mathrm{mM}$ and $200 \mathrm{mM} \mathrm{NaCl}$. Callus size and weight is the indicator for salt tolerance. So, the callus diameter and weight were assayed twice after treating with different salt concentrations. Initial weight and diameter of each callus of every genotype were also measured to compare with those 
data which were taken after 10 days and 17 days after treating $\mathrm{NaCl}$. The callus growth was the highest in control condition $(0 \mathrm{mM}$ of $\mathrm{NaCl})$ and gradually decreases as the salt stress increases that is $50 \mathrm{mM}, 100 \mathrm{mM}, 150 \mathrm{mM}$ and $200 \mathrm{mM}$. The callus diameter and fresh weight were measured and the results obtained from these studies have been presented and discussed separately under different headings. Each of the parameter as influenced by genotypes, treatments and their interactions were discussed below.

\section{Biomass changing of callus under salt stress at $10 \mathrm{DAT}$}

Size and weight of callus of six genotypes were recorded for 10 days after treatment in different $\mathrm{NaCl}$ concentration and significant differences were recorded (Plate 4 and Fig. 1). After 10 days of treatment in case of G6 the highest biomass size was recorded up to $50 \mathrm{mM}$ salt concentration and the lowest was recorded in G5 up to $100 \mathrm{mM}$ salt concentrations. In case of $100 \mathrm{mM}$ the highest biomass size was found in G2 and it was static upto $200 \mathrm{mM}$ salt concentration and the lowest size was found in G1 for both $150 \mathrm{mM}$ and $200 \mathrm{mM}$ salt concentrations. Genotypic variation for biomass size is evident in control $(0 \mathrm{mM})$ and in stressed condition $(50 \mathrm{mM}, 100 \mathrm{mM}, 150 \mathrm{mM}$ and 200 $\mathrm{mM}$ ) (Fig. 1A). Biomass size reduced gradually as the salt concentration increases. Variable callus size was obtained at 10 DAT in different genotypes.

So, the size of root reduction per treatment was evaluated (Fig. 1B). Callus size reduction is negative in G5 from 50
$\mathrm{mM}$ to $100 \mathrm{mM}$, that is root was not reduced at $100 \mathrm{mM}$ rather increased than that of $50 \mathrm{mM}$. G2 also showed better performance at $50 \mathrm{mM}$. The biomass size was almost similar to control. G4 size reduced at $50 \mathrm{mM}$ but after that at $100 \mathrm{mM}$ it was similar as in $50 \mathrm{mM}$ (Fig. 1B). After 10 days of treatment in case of G6 the highest biomass weight was recorded upto $50 \mathrm{mM}$ salt concentration whereas biomass size of G5was the lowest from $0 \mathrm{mM}$ to $50 \mathrm{mM}$ salt concentrations In case of $100 \mathrm{mM}$ the highest biomass weight was found in G2 and it was static up to $200 \mathrm{mM}$ salt concentration and thelowest weight was found in G6 for $100 \mathrm{mM}$ and the lowest biomass weight was found in G6 for both $100 \mathrm{mM}$ and $150 \mathrm{mM}$. In case of $200 \mathrm{mM}$ the lowest weight was recorded for G3. Genotypic variation for biomass weight is evident in control $(0 \mathrm{mM})$ and in stressed condition (50 mM, $100 \mathrm{mM}, 150 \mathrm{mM}$ and $200 \mathrm{mM}$ ) (Fig. 2A). G2 did not loss much weight under $50 \mathrm{mM}$ salt stress (Fig. 2B). Gradually it reducedweight but at severe stress $(200 \mathrm{mM})$ it was showed tolerance to salt (Fig. 2B). Reduction in growth with increasing salinity in growth media may be attributed to water deficit or ion toxicity associated with excessive ion uptake particularly of [Na.sup.+] and [Cl.sup.-] (Satti and Lopez, 1994). Nutrientsimbalance as a result of depressed uptake, shoot transport and impaired internal distribution of minerals especially [K.sup.+] and [Ca.sup.+2] may also explained the reduction in plant growth (Munns, 2008). 


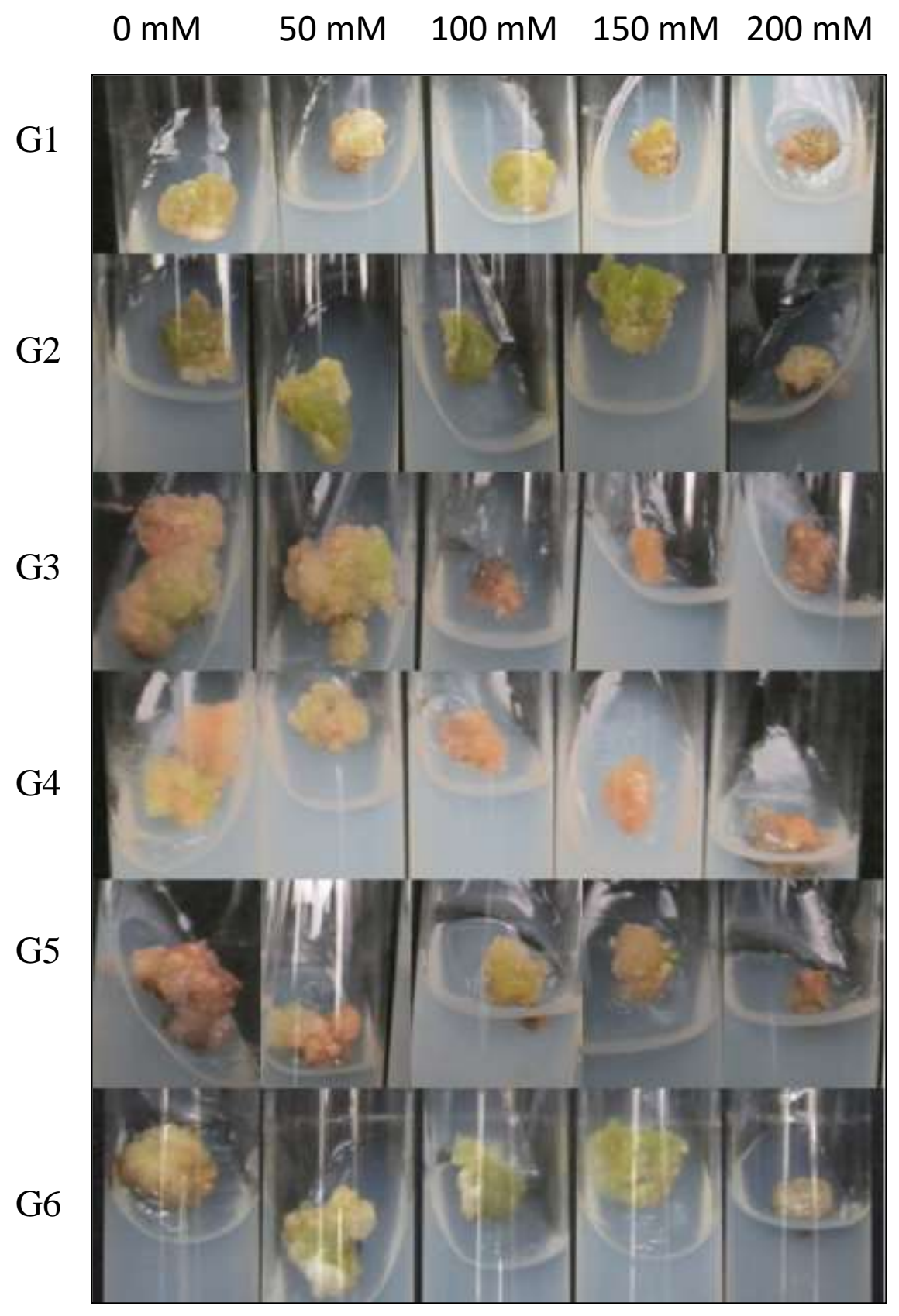

Plate.4: Biomass changing of callus under salt stress at 10 DAT. 

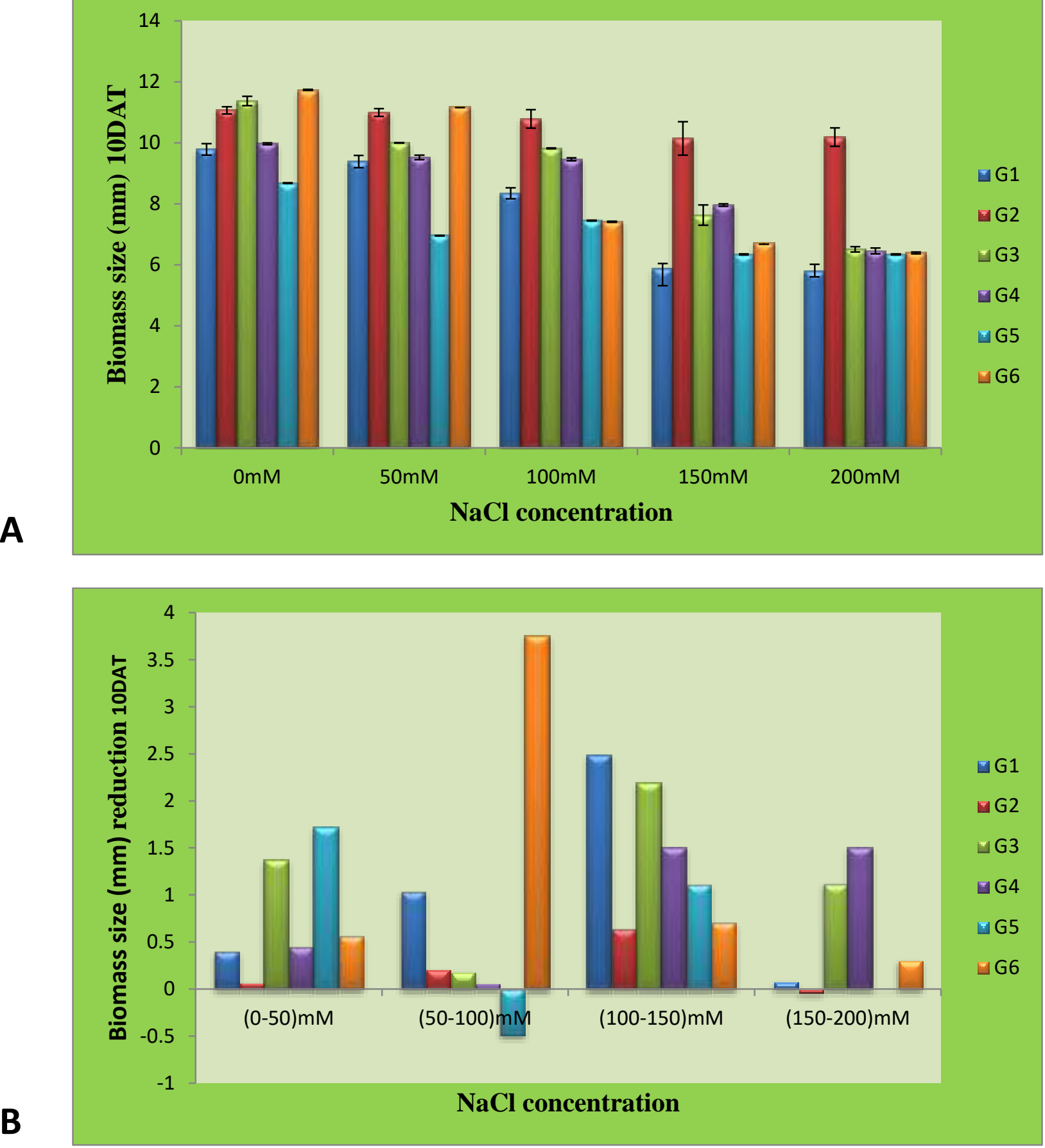

Fig.1: Biomass changing of callus size under salt stress at 10 DAT

\section{A. Mean Biomass size. B. Mean Biomass size reduction 10DAT}

Biomass changing of callus under salt stress at 17 DAT

Size and weight of callus of six genotypes were recorded for 17 days after treatment in different $\mathrm{NaCl}$ concentration and significant differences were recorded (Plate 5 and Fig. 3). After 17 days biomass size was the highest in $\mathrm{G} 4$ at 0 $\mathrm{mM}$ and the lowest size was found in $\mathrm{G} 3$ at $0 \mathrm{mM}$ to 50 $\mathrm{mM}$. From $50 \mathrm{mM}$ to $100 \mathrm{mM}$ the highest size was recorded for G5.The highest size was recorded for $\mathrm{G} 2$ from $150 \mathrm{mM}$ to $200 \mathrm{mM}$ whereas the lowest size was recorded for $\mathrm{G} 1$ for both of these concentrations (Fig. 3A). The G2 was not significantly reduced in biomass size under $50 \mathrm{mM}$ to 100 $\mathrm{mM}$ salt. G6 was significantly reduced under light salt stress $(50 \mathrm{mM})$ but later became stable up to $200 \mathrm{mM}$ salt concentrations. G2 and G3 callus also showed stable condition in size from lower to higher salt stress because 
size was not significantly reduced from control condition to stress condition (Fig 3B).

After 17 days, biomass weight was the highest in G2 from low stress $(50 \mathrm{mM})$ up to the severe stress $(200 \mathrm{mM})$ and size was almost same in control to severe stress condition indicating its tolerance. The lowest weight was found in G3 from $0 \mathrm{mM}$ to $200 \mathrm{mM}$ (Fig. 4A). There was no significant biomass weight reduction in $\mathrm{G} 2$ from control $(0 \mathrm{mM})$ to severe stress $(200 \mathrm{mM})$ condition. G6 has the lowest tolerance up to $50 \mathrm{mM}$ regarding its weight but from 150 $\mathrm{mM}$ to $200 \mathrm{mM}$ it recovered and showed slight tolerance (Fig. 4B). The addition of $\mathrm{NaCl}$ to the culture media decreased the osmotic potential of the media

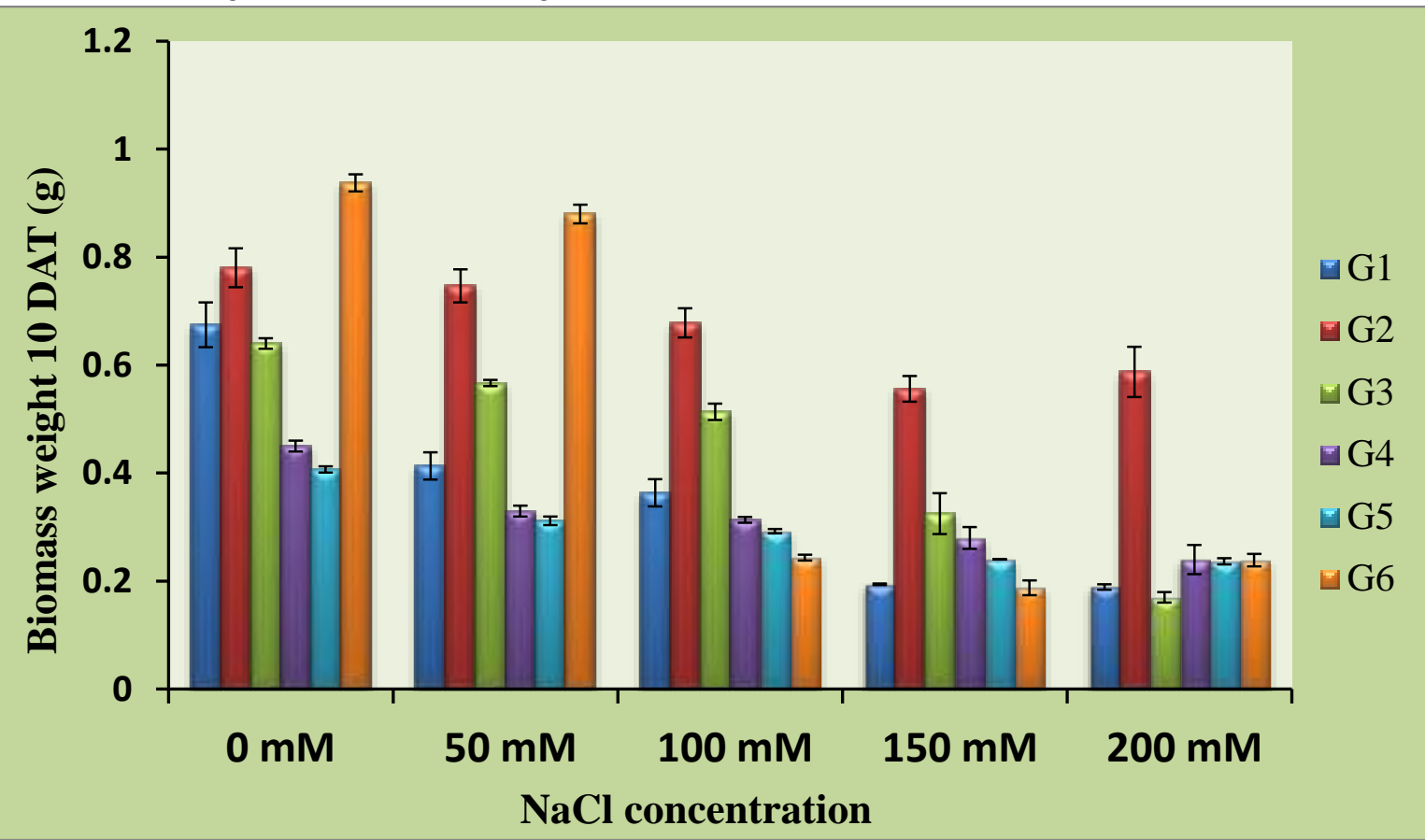

A

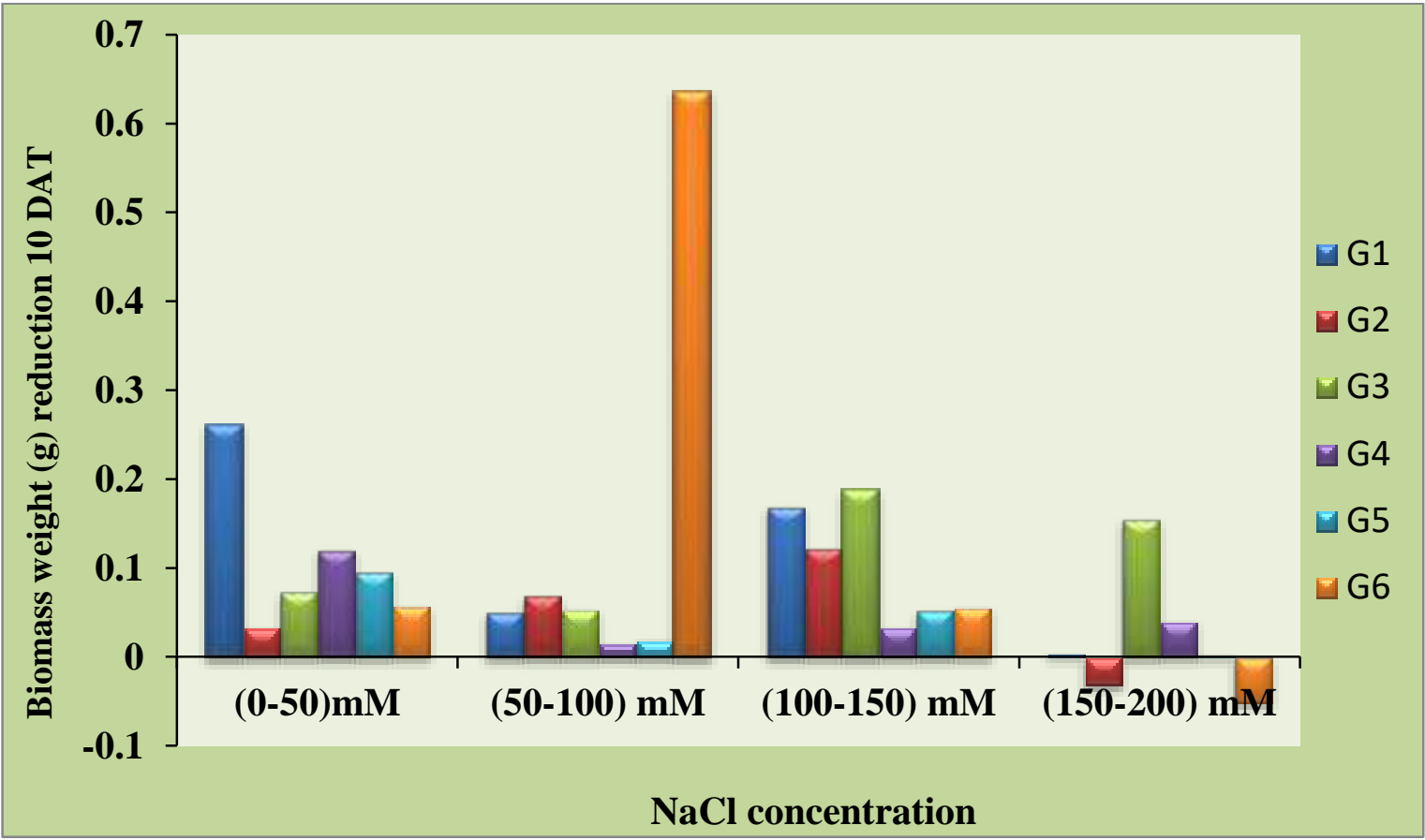

Fig.2: Biomass changing of callus weight under salt stress at 10 DAT A. Mean Biomass weight. B. Mean Biomass weight reduction at 10DAT 


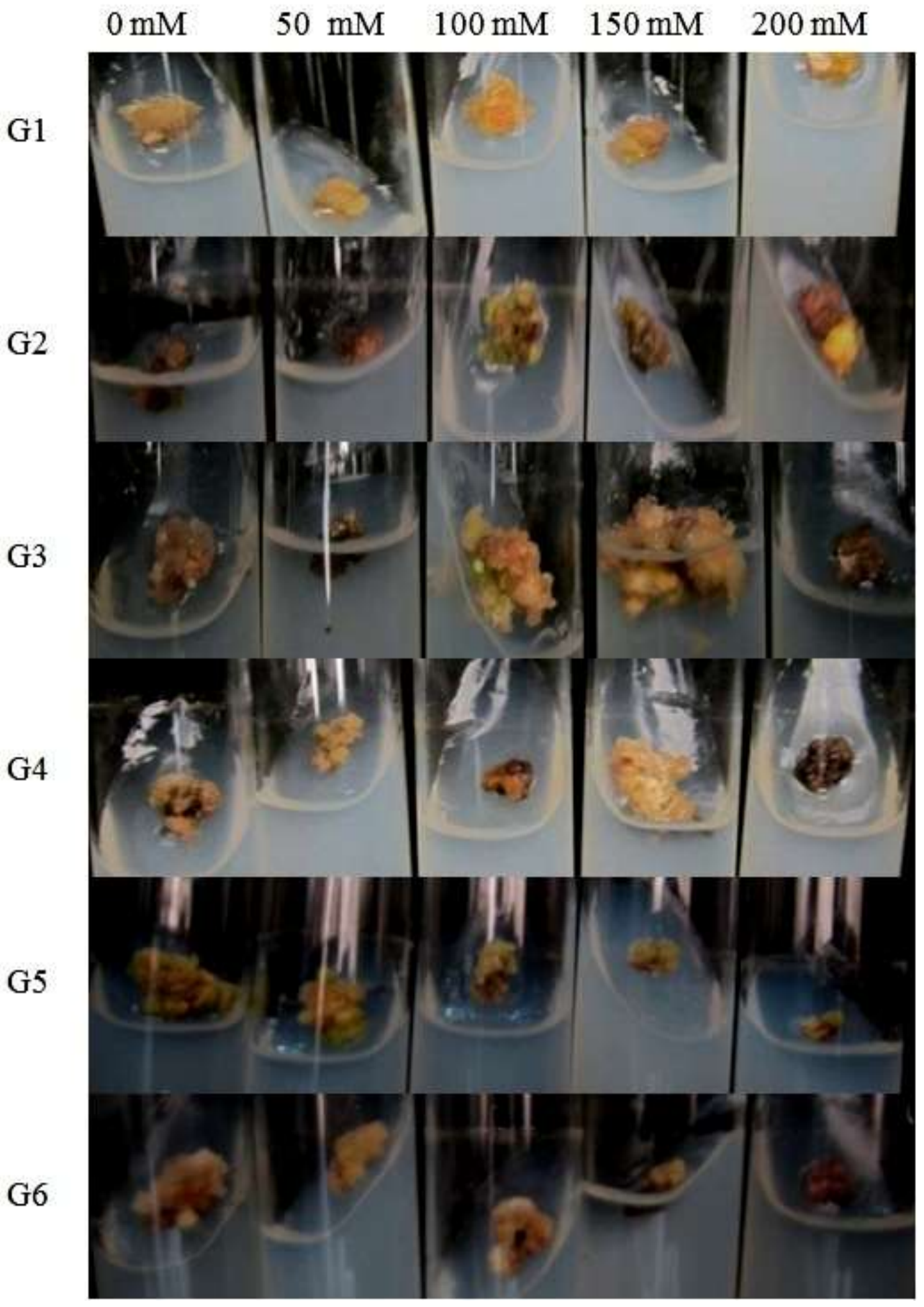

Plate.5: Biomass changing of callus under salt stress at 17 DAT. 
A

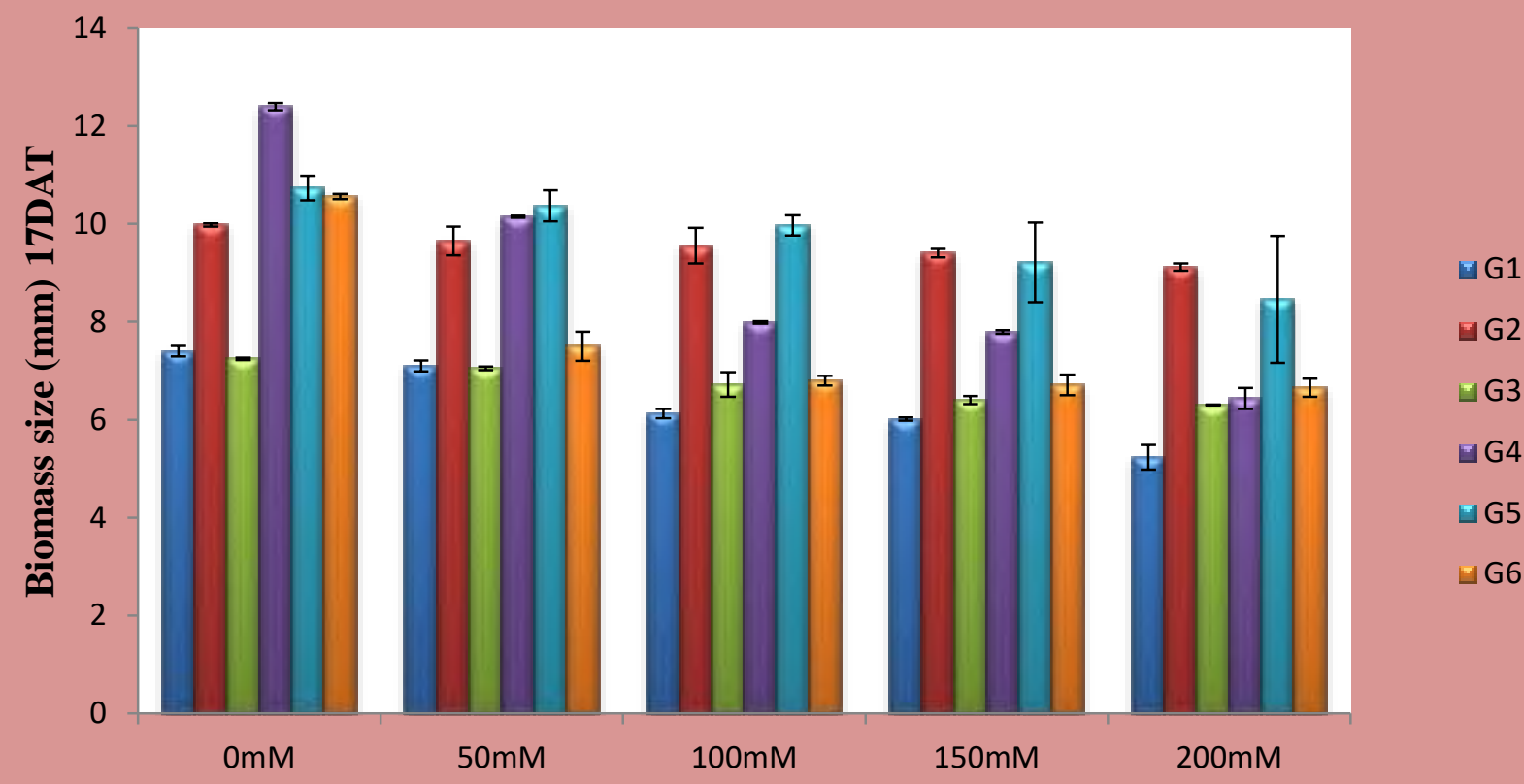

Nacl concentration

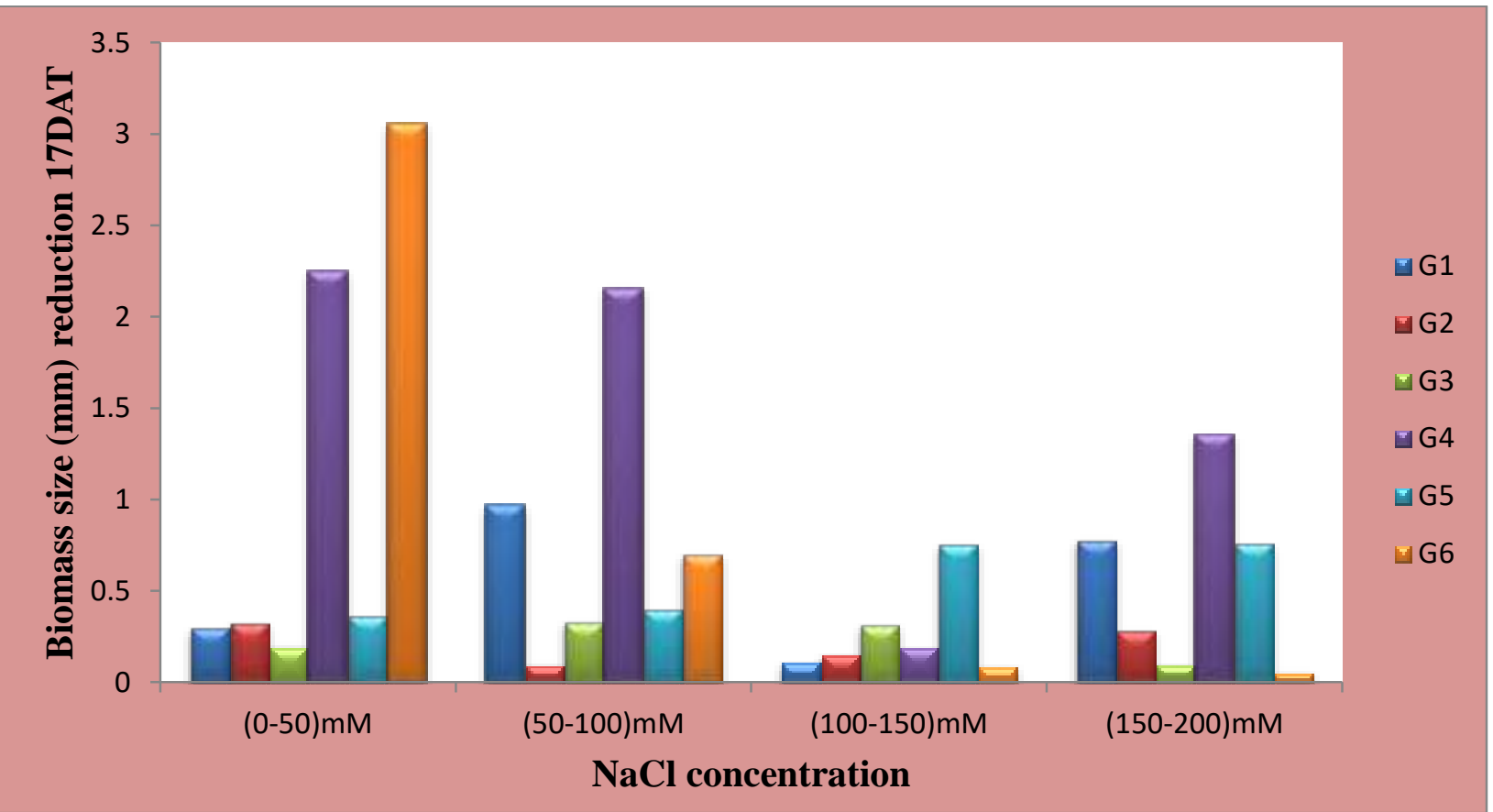

Fig .3: Biomass changing of callus size under salt stress at 17 DAT

A. Mean Biomass size. B. Mean Biomass size reduction 17DAT

inducing salinity stress that adversely affected the callus growth and in vitro regeneration capacity of tomato cultivars. In this study G2 showed moretolerance than the other genotypes might be due the osmotic adjustment. Yang et al. (1990) reported that osmotic adjustment in callus results from both $\mathrm{Na}+$ and $\mathrm{Cl}$ - accumulation. Similar results have been reported for calli of wheat genotypes (Farrukh, 2002). The tolerance of G2 might also be due to the accumulation of proline under stress condition. Proline protects hydration shell in the cell and helps protect from denaturation of protein. Aazami et al. (2010) was also in agreement with this concept. With increasing of $\mathrm{NaCl}$, the 
proline content of all cultivars significantly increased in the study of Aazami et al. (2010). The rates of accumulation were different depending on cultivars and $\mathrm{NaCl}$ levels. The results are in agreement with Emilio et al. (1998) for $L$. esculentum and Lecopersicon pennellii. Marthinez et al. (1996) reported a positive relationship between proline accumulation and $\mathrm{NaCl}$ tolerance in potato (Mohamed et al., 2007). Salt tolerance also depends on the antioxidative defense. In spite of the large number of publications on the role of antioxidative defense under salt stress, the relative importance of this process to overall plant salt tolerance is still a matter of controversy. More study are needed for the generation and scavenging of reactive oxygen species (ROS) under normal and salt stress conditions in relation to the type of photosynthesis which are directly related to the stress tolerance because they scavenge toxic compounds in the cell.
Biomass changing in genotype, treatment and their interaction

Biomass changing of callus on genotypes

Salt treatment was given in every genotype and data were taken 10 DAT and 17 DAT. The highest size (diameter) of callus was found in the $\mathrm{G} 2(10.63 \mathrm{~mm})$ at 10 Days After Treatment (DAT) of callus (Table 2) but it was changed after 17 days and G2(9.539 mm)and G5 $(9.749 \mathrm{~mm})$ both of them werereached in the highest point. The lowest size of callus was found in G5 at 10 DAT $(7.153 \mathrm{~mm})$ and at 17 DAT G1 had the lowest size of callus (6.375). The highest weight was found in G2 for both 10DAT (0.6693 g) and 17DAT $(0.8100 \mathrm{~g})$. The lowest weight of callus was found in G4 (0.3227 g) and in G5 (0.2980 g) at 10 DAT (Table 2). At 17 DAT, G2 showed the highest callus weight $(0.8100 \mathrm{~g})$ and G3 showed the lowest callus weight (0.3593 g). Significant differences were also found

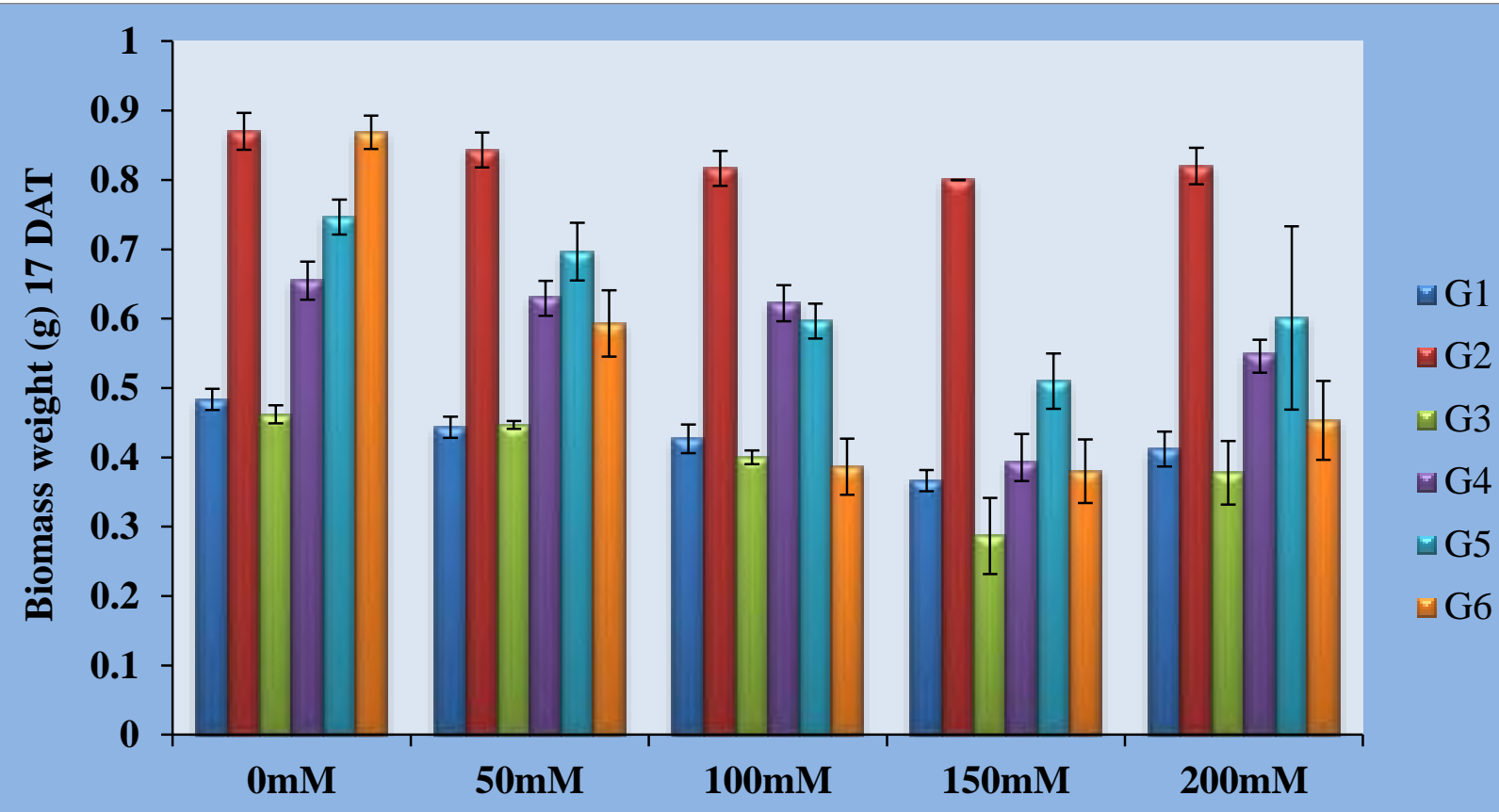




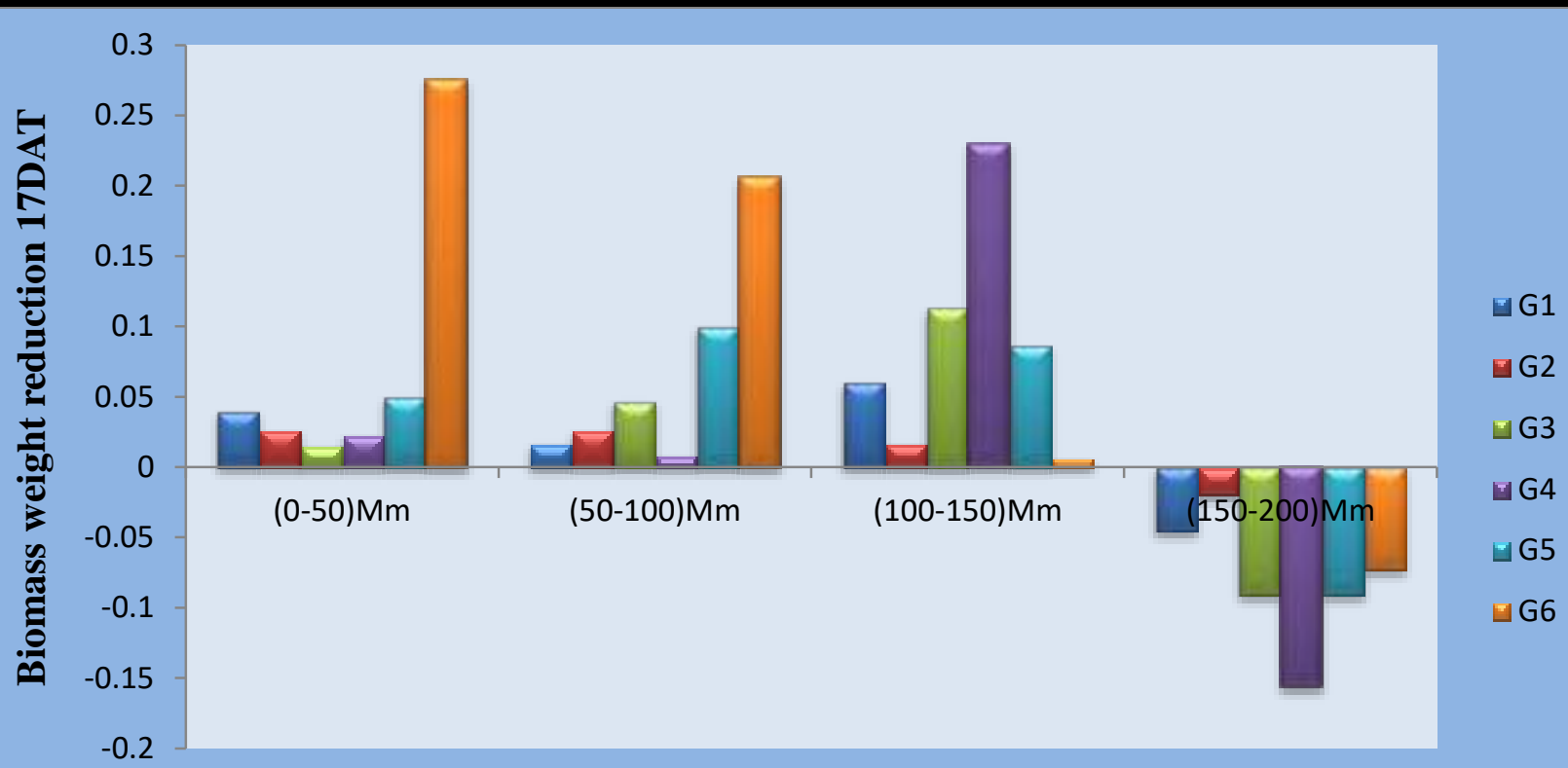

B

\section{NaCl concentration}

Fig 4. Biomass changing of callus weight under salt stress at 17 DAT

\section{A. Mean Biomass weight. B. Mean Biomass weight reduction at 17 DAT}

among cultivars regarding above traits by Aazami et al. (2010). Similar results were also found by other researchers (Vijayan et al., 2003; Tewary et al., 2000; Ben-Hayyim, 1987).

\section{Biomass changing of callus on treatment}

The main effect of different concentrations of salt showed significant variation on biomass changing of callus at different DAT. In all of the genotypes $0 \mathrm{mM}$ salt treatment showed the best result whereas $200 \mathrm{mM}$ showed the worst result (Table 3). Any increase in salinity levels in the media led to decrease of callus growth was also found by Aazami et al. (2010).

\section{Biomass changing of callus on Genotype $X$ Treatment interaction}

The combined effect of genotypes and different concentrations (treatments) of salt showed significant variation on biomass changing of callus at different DAT. At 10 DAT the highest callus size was observed in G6T1 $(11.73 \mathrm{~mm})$ that is $\mathrm{G} 6$ treated with $\mathrm{T} 1$ and the lowest callus size was $(5.783 \mathrm{~mm})$ in G1T4 and G1T5. At 17 DAT, the highest biomass size was $(12.40 \mathrm{~mm})$ in G4T1 and the lowest callus size was in G1T5 $(5.233 \mathrm{~mm})$ (Table 4). As the salt concentration increases, the callus size decreases in
G1 at 10 DAT as well as in 17 DAT. There was significant interaction effect between the genotypes and salt concentrations on callus weight also at 10 DAT and 17 DAT. In case of weight also all of the genotypes showed gradual decrease of weight from T1 to T5 at 10 DAT and at 17 DAT. In other genotypes also from G2 to G6, the biomass size of callus and weight were decreases gradually from $0 \mathrm{mM}$ (T1) to $200 \mathrm{mM}$ (T5) concentrations at 10 DAT as well as 17 DAT. The addition of $\mathrm{NaCl}$ to the culture media decreased the osmotic potential of the media inducing salinity stress that adversely affected the callus growth. Several authors reported the use of $\mathrm{NaCl}$ for in vitro salinity screening in different plants (Vijayan et al., 2003). In this study, the adaption capacity to different salt level varies with the genotype's degree of tolerance. The genotypic variation for salt tolerance in this study agreed with the result of Rus et al. (2001) and Perez-Alfocea et al. (1994) who detected different salt stress responses among several tomato cultivars, from an halophytic behavior. Callus growing in this study under the increasing $\mathrm{NaCl}$ concentrations reduced relative growth rate in all tomato cultivars as in the study of Ben-Hayyim, 1987, Zhang et al. 2004 and Amini and Ehsanpour, 2006. In vitro plant tissue culture is useful and quick tool to evaluate plant tolerance to salt stress. Many studies were carried out. 
Table.2: Biomass changing of callus on genotypes

\begin{tabular}{|c|c|c|c|c|}
\hline Genotype & $\begin{array}{c}\text { Biomass size after } 10 \\
\text { days }(\mathbf{m m})\end{array}$ & $\begin{array}{c}\text { Biomass size after } 17 \\
\text { days }(\mathbf{m m})\end{array}$ & $\begin{array}{l}\text { Biomass weight } \\
\text { after 10days (g) }\end{array}$ & $\begin{array}{l}\text { Biomass weight } \\
\text { after } 17 \text { days (g) }\end{array}$ \\
\hline $\mathbf{G}_{1}$ & $7.833 \quad \mathrm{~d}$ & $6.375 \quad \mathrm{e}$ & $0.4633 \mathrm{~b}$ & $0.4087 \quad \mathrm{~d}$ \\
\hline$\overline{\mathbf{G}_{2}}$ & $10.63 \mathrm{a}$ & 9.539 & $0.6693 \mathrm{a}$ & 0.8100 \\
\hline $\mathbf{G}_{3}$ & $9.064 \mathrm{~b}$ & $6.745 \quad \mathrm{~d}$ & $0.4433 \mathrm{~b}$ & 0.3593 \\
\hline $\mathbf{G}_{4}$ & $8.672 \mathrm{c}$ & 8.951 & $0.3227 \mathrm{c}$ & 0.5107 \\
\hline $\mathbf{G}_{5}$ & $7.153 \mathrm{e}$ & 9.749 & $0.2980 \mathrm{c}$ & 0.5940 \\
\hline $\mathbf{G}_{6}$ & 8.686 & 7.645 & $0.4973 \mathrm{~b}$ & 0.5173 \\
\hline $\begin{array}{l}\mathbf{s}_{-} \\
\mathbf{x}\end{array}$ & 0.04397 & 0.08406 & 0.02828 & 0.01155 \\
\hline
\end{tabular}

$\mathrm{G} 1=\mathrm{BD}-7755, \mathrm{G} 2=\mathrm{BD}-7757, \mathrm{G} 3=\mathrm{BD}-9008, \mathrm{G} 4=\mathrm{BD}-9011, \mathrm{G} 5=\mathrm{BD}-10122, \mathrm{G} 6=\mathrm{BD}-10123$.

Table.3: Biomass changing of callus on Treatment

\begin{tabular}{|c|c|c|c|c|}
\hline Treatment & $\begin{array}{c}\text { Biomass size after 10 } \\
\text { days (mm) }\end{array}$ & $\begin{array}{c}\text { Biomass size after 17 } \\
\text { days }(\mathbf{m m})\end{array}$ & $\begin{array}{c}\text { Biomass weight } \\
\text { after 10days (g) }\end{array}$ & $\begin{array}{c}\text { Biomass weight } \\
\text { after 17days (g) }\end{array}$ \\
\hline $\mathbf{T}_{\mathbf{1}}$ & $10.43 \mathrm{a}$ & $9.719 \mathrm{a}$ & $0.6478 \mathrm{a}$ & $0.6811 \mathrm{a}$ \\
\hline $\mathbf{T}_{\mathbf{2}}$ & $9.670 \mathrm{~b}$ & $8.636 \mathrm{~b}$ & $0.5417 \mathrm{~b}$ & $0.6094 \mathrm{~b}$ \\
\hline $\mathbf{T}_{\mathbf{3}}$ & $8.879 \mathrm{c}$ & $7.859 \mathrm{c}$ & $0.4006 \mathrm{c}$ & $0.5417 \mathrm{c}$ \\
\hline $\mathbf{T}_{\mathbf{4}}$ & $7.441 \mathrm{~d}$ & $7.589 \mathrm{~d}$ & $0.3389 \mathrm{~cd}$ & $0.4561 \mathrm{~d}$ \\
\hline $\mathbf{T}_{\mathbf{5}}$ & $6.946 \mathrm{e}$ & $7.033 \mathrm{e}$ & $0.3161 \mathrm{~d}$ & $0.3783 \mathrm{e}$ \\
\hline $\mathbf{s}_{-}$ & $\mathbf{0 . 0 4 0 1 4}$ & $\mathbf{0 . 0 7 6 7 4}$ & $\mathbf{0 . 0 2 5 8 2}$ & $\mathbf{0 . 0 1 0 5 4}$ \\
$\mathbf{x}$ & & & & \\
\hline
\end{tabular}

$\mathrm{T} 1=0 \mathrm{mM}, \mathrm{T} 2=50 \mathrm{mM}, \mathrm{T} 3=100 \mathrm{mM}, \mathrm{T} 4=150 \mathrm{mM}, \mathrm{T} 5=200 \mathrm{mM}$.

Table.4: Interaction effect of genotype and treatment

\begin{tabular}{|c|c|c|c|c|}
\hline Interaction & $\begin{array}{c}\text { Biomass size after } 10 \\
\text { days (mm) }\end{array}$ & $\begin{array}{c}\text { Biomass size after } 17 \\
\text { days (mm) }\end{array}$ & $\begin{array}{l}\text { Biomass weight } \\
\text { after 10days (g) }\end{array}$ & $\begin{array}{l}\text { Biomass weight } \\
\text { after 17days (g) }\end{array}$ \\
\hline $\mathbf{G}_{1} \mathbf{T}_{1}$ & $9.783 \mathrm{fg}$ & $7.400 \mathrm{jk}$ & 0.6733 b-d & 0.4833 gh \\
\hline $\mathbf{G}_{1} \mathbf{T}_{2}$ & $9.383 \mathrm{~h}$ & $7.100 \mathrm{kl}$ & $0.4133 \quad \mathrm{f}-\mathrm{i}$ & $0.4433 \quad g-j$ \\
\hline $\mathbf{G}_{1} \mathbf{T}_{3}$ & $8.347 \mathrm{j}$ & $6.127 \mathrm{no}$ & $0.3633 \quad g-j$ & 0.4267 h-k \\
\hline $\mathbf{G}_{1} \mathbf{T}_{4}$ & $5.867 \mathrm{p}$ & $6.013 \mathrm{o}$ & 0.4433 e-i & $0.3667 \quad j-1$ \\
\hline $\mathbf{G}_{1} \mathbf{T}_{5}$ & $5.783 \mathrm{p}$ & $5.233 \mathrm{p}$ & 0.4233 f-i & $0.3233 \quad 1-n$ \\
\hline $\mathbf{G}_{2} \mathbf{T}_{1}$ & $11.06 \mathrm{~cd}$ & $9.97 \mathrm{~d}-\mathrm{f}$ & $0.7800 \mathrm{ab}$ & $0.8700 \quad \mathrm{a}$ \\
\hline $\mathbf{G}_{2} \mathbf{T}_{2}$ & $10.99 \mathrm{~cd}$ & $9.65 \mathrm{e}-\mathrm{g}$ & 0.7467 a-c & $0.8433 \quad \mathrm{a}$ \\
\hline $\mathbf{G}_{2} \mathbf{T}_{3}$ & $10.78 \mathrm{~d}$ & $9.55 \mathrm{e}-\mathrm{g}$ & $0.6767 \mathrm{~b}-\mathrm{d}$ & $0.8167 \mathrm{ab}$ \\
\hline $\mathbf{G}_{2} \mathbf{T}_{4}$ & $10.14 \mathrm{e}$ & $9.400 \mathrm{fg}$ & $0.5567 \quad \mathrm{c}-\mathrm{g}$ & $0.8000 \mathrm{ab}$ \\
\hline $\mathbf{G}_{2} \mathbf{T}_{5}$ & $10.19 \mathrm{e}$ & $9.117 \mathrm{~g}$ & 0.5867 b-f & $0.7200 \mathrm{~cd}$ \\
\hline $\mathbf{G}_{3} \mathbf{T}_{1}$ & $11.37 \mathrm{~b}$ & $7.2 \quad \mathrm{j}-1$ & $0.6400 \quad b-e$ & $0.4633 \quad \mathrm{~g}-\mathrm{i}$ \\
\hline $\mathbf{G}_{3} \mathbf{T}_{2}$ & 9.997 ef & $7.050 \mathrm{kl}$ & $0.5667 \quad \mathrm{c}-\mathrm{g}$ & $0.4467 \quad \mathrm{~g}-\mathrm{j}$ \\
\hline $\mathbf{G}_{3} \mathbf{T}_{3}$ & $9.817 \mathrm{f}$ & $6.7 \quad 1-n$ & $0.5133 \mathrm{~d}-\mathrm{h}$ & 0.4000 h-1 \\
\hline $\mathbf{G}_{3} \mathbf{T}_{4}$ & $\begin{array}{ll}7.630 \quad 1 \\
\end{array}$ & $6.4 \mathrm{~m}-\mathrm{o}$ & $0.3267 \quad h-j$ & $0.2867 \mathrm{mn}$ \\
\hline G3 $_{3} \mathbf{T}_{5}$ & 6.510 no & $6.303 \mathrm{~m}-\mathrm{o}$ & $0.1700 \quad \mathrm{j}$ & $0.2000 \quad$ o \\
\hline $\mathbf{G}_{\mathbf{4}} \mathbf{T}_{1}$ & 9.97 ef & $12.40 \mathrm{a}$ & $0.4500 \mathrm{e}-\mathrm{i}$ & 0.6533 d-f \\
\hline $\mathbf{G}_{\mathbf{4}} \mathbf{T}_{\mathbf{2}}$ & $9.520 \mathrm{gh}$ & $10.1 \mathrm{c}-\mathrm{e}$ & $0.3300 \mathrm{~h}-\mathrm{j}$ & 0.6333 ef \\
\hline
\end{tabular}




\begin{tabular}{|c|c|c|c|c|}
\hline $\mathbf{G}_{\mathbf{4}} \mathbf{T}_{3}$ & $9.460 \mathrm{~h}$ & $7.987 \mathrm{hi}$ & $0.3133 \mathrm{~h}-\mathrm{j}$ & 0.6233 \\
\hline$\overline{\mathbf{G}_{4} \mathbf{T}_{4}}$ & $7.957 \mathrm{k}$ & $7.793 \mathrm{ij}$ & $0.2800 \quad \mathrm{ij}$ & $0.3933 \quad \mathrm{i}-1$ \\
\hline$\overline{\mathbf{G}_{4} \mathbf{T}_{5}}$ & 6.45 no & $6.4 \mathrm{~m}-\mathrm{o}$ & 0.2400 ij & 0.2500 no \\
\hline $\mathbf{G}_{5} \mathbf{T}_{1}$ & $8.680 \mathrm{i}$ & $10.73 \mathrm{~b}$ & $0.406 \mathrm{f}-\mathrm{i}$ & $0.7467 \quad b c$ \\
\hline $\mathbf{G}_{5} \mathbf{T}_{2}$ & $6.960 \mathrm{~m}$ & $10.37 \mathrm{~b}-\mathrm{d}$ & $0.313 \mathrm{~h}-\mathrm{j}$ & 0.6967 c-e \\
\hline$G_{5} T_{3}$ & $7.450 \quad 1$ & $9.970 \mathrm{c}-\mathrm{f}$ & $0.293 \mathrm{ij}$ & $0.5967 \quad f$ \\
\hline $\mathbf{G}_{5} \mathbf{T}_{4}$ & $6.337 \quad$ o & $9.217 \mathrm{~g}$ & $0.240 \quad \mathrm{ij}$ & $0.5100 \quad \mathrm{~g}$ \\
\hline $\mathbf{G}_{5} \mathbf{T}_{5}$ & $6.33 \quad \mathrm{o}$ & $8.457 \mathrm{~h}$ & $0.236 \mathrm{ij}$ & 0.420 h-k \\
\hline$\overline{\text { G6 }_{6} \mathbf{T}_{1}}$ & $11.73 \mathrm{a}$ & $10.56 \mathrm{bc}$ & $0.9367 \mathrm{a}$ & $0.8700 \quad \mathrm{a}$ \\
\hline G6 $_{6} T_{2}$ & $11.17 \mathrm{bc}$ & $7.500 \mathrm{i}-\mathrm{k}$ & $0.8800 \mathrm{a}$ & $0.5933 \mathrm{f}$ \\
\hline$\overline{G_{6} T_{3}}$ & $\begin{array}{ll}7.41 & 1\end{array}$ & $6.800 \mathrm{~lm}$ & $0.2433 \mathrm{ij}$ & $0.3867 \quad$ i-1 \\
\hline $\mathbf{G}_{6} \mathbf{T}_{4}$ & $6.710 \mathrm{mn}$ & $6.7101-n$ & $0.186 \mathrm{j}$ & 0.3800 i-1 \\
\hline $\mathbf{G}_{6} T_{5}$ & $6.403 \quad$ o & $6.6531-n$ & $0.24 \quad \mathrm{ij}$ & $0.3567 \mathrm{k}-\mathrm{m}$ \\
\hline $\begin{array}{l}\mathbf{s}_{-} \\
\mathbf{x}\end{array}$ & 0.09832 & 0.1880 & 0.06325 & 0.02582 \\
\hline CV\% & 1.98 & 3.99 & 24.21 & 7.33 \\
\hline
\end{tabular}

$\mathrm{G} 1=\mathrm{BD}-7755, \mathrm{G} 2=\mathrm{BD}-7757, \mathrm{G} 3=\mathrm{BD}-9008, \mathrm{G} 4=\mathrm{BD}-9011, \mathrm{G} 5=\mathrm{BD}-10122, \mathrm{G} 6=\mathrm{BD}-10123, \mathrm{~T} 1=0$ $\mathrm{mM}, \mathrm{T} 2=50 \mathrm{mM}, \mathrm{T} 3=100 \mathrm{mM}, \mathrm{T} 4=150 \mathrm{mM}, \mathrm{T} 5=200 \mathrm{mM}$

Through using different tissue culture methods (Bhatia et al., 2008). The callus induction potential was decreased with increasing $\mathrm{NaCl}$ levels in this study. A similar observation was found by Yusuf et al. (1994), Cano et al. (1998) and Mercado et al. (2000) in tomato using tissue culture techniques for in vitro selection for salinity tolerance. Cultivated tomato is generally classified as being moderately salt-sensitive. Different genotypes of tomato displayed widely different degrees of salinity tolerance (Ghoshal and Bajaj, 1984). Marked differences in the behavior of both susceptible and tolerant tomato genotypes were evident (Cano et al., 1998; Rus et al., 2001). Yet, an understanding of the mechanisms that plants use to cope with high salinity is necessary to select and develop tomato plants that are more tolerant to salinity.

\section{REFERENCES}

[1] Aazami, M.A., Torabi, M. and Shekari, F. 2010. Response of some tomato cultivars to sodium chloride stress under in vitro culture condition. African J. Agril. Res. 5(18): 2589-2592.

[2] Aditya, T.L., Rahman, L., Shah-E-Alam, M. and Ghosh, A.K. 1999. Correlation and Path Coefficient Analysis in Tomato. Bangladesh Agril. Sci. 26(1):119122.

[3] Amini, F., Ehsanpour, A.A. 2006. Response of tomato (Lycopersicon esculentum Mill.) cultivars to MS, water agar and salt stress in in vitro culture. Asian J. Plant Sci., 9(1): 170-175.
[4] Ben-Hayyim, G. 1987. Relationship between salt tolerance and resistance to polyethylene glycolinduced water stress in cultured citrus cells. Plant Physiol. 85: 430-433.

[5] Bhatia P., and Ashwath, N. 2008. Improving the quality of in vitro cultured shoots of tomato (Lycopersicon esculentum Mill. cv. Red Coat. Biotechnol. 7(2): 188-193.

[6] Cano, E.A., Perez, A., Moreno, V., Caro, M., and Bolarin, M. 1998. Evaluation of salt tolerance in cultivated and wild tomato species through in vitro shoot apex culture. Plant Cell Tiss. Organ Cul., 53 (1): 19-26.

[7] Cuartero, J., and Fernández-Muñoz, R. 1999. Tomato and salinity. Scientia Horticulturae, 78: 83125.

[8] Cuartero, J., Boları'n, M.C., Ası'ns, M.J., and Moreno, V. 2006. Increasing salt tolerance in the tomato. J. Exp. Bot. 57(5): 1045-1058.

[9] Farrukh, J. 2002. In vitro salt tolerance in wheat. III. Water relations in callus. Int. J. Agri. Biol. 4(4): 665667.

[10]Flowers, T.J., and Yeo, A.R. 1995. Breeding for salinity resistance in crop plants: where next? Aust. J. Plant Physiol., 22: 875-884.

[11] Ghosal, S.S., and Bajaj, Y.P.S. 1984. Isolation of sodium chloride resistant cell lines in some grain legumes. Indian J. Exp. Biol., 22: 209-214.

[12] Martinez, C.A., Maestri, M., and Lani, E.G. 1996. In vitro salt tolerance and proline accumulation in andean potato (Solanum spp.) differing in frost resistance. Plant Sci., 116: 177-184. 
[13] Mercado, J.A., Sancho, Jimenez, B.S., Peran, U.R., Pliego, A.F., and Quesada, M.A. 2000. assessment of in vitro growth of apical stem sections and adventitious organogenesis to evaluate salinity tolerance in cultivated tomato. Plant Cell Tiss. Organ Cul., 62: 101-106.

[14] Mohamed, A.N., Rahman, M.H., Alsadon, A.A. and Islam, R. 2007. Accumulation of proline in NaCltreated callus of six tomato (Lycopersicon esculentum Mill.) cultivars. Plant Tissue Cult. Biotech. 17(2): 217-220.

[15] Perez-Alfocea, F., Guerrier, G., Estañ, M.T. and Bolarin, M.C. 1994 Comparative salt responses at cell and whole-plant levels of cultivated and wild tomato species and their hybrid. J. Hort. Sci. 69: 639-644

[16] Rus, A.M., Estañ, M.T., Gisbert, C., Garcia-Sogo, B., Serrano, R., Caro, M., Moreno, V., and Bolarín, M.C. 2001. Expressing the yeast HAL1 gene in tomato increases fruit

[17] Shatnawi, M.A. 2006. Micropropagation and germplasm storage of Prunus amygdalus by the vitrification method. Jordan J. Agric. Sci.6(4): 446450.

[18] Tal, M, Heikin H and Dehan K 1978 Salt tolerance in the wild relatives of the cultivated tomato: responses of callus tissues of Lycopersicon esculentumand Solanum pennellito high salinity. Z. Pflanzenphysiol. 86: 231-240.

[19] Tewary, P.K., Sharma, A., Raghunath, M. K. and Sarkar, A. 2000. In vitro response of promising mulberry (Morus sp.) genotypes for tolerance to salt and osmotic stresses. Plant Grow. Regul. 30: 17-21

[20] Vijayan, K., Chakraborti, S.P. and Ghosh, P.D. 2003. In vitro screening of mulberry (Morus spp.) for salinity tolerance.Plant Cell Rep. 22: 350-357.

[21] Yang, Y.W., Newton, R. J. and Miller, F. R. 1990. Salinity tolerance in sorghum. II. Cell culture response to sodium chloride in $S$. bicolor and S. halepense. Crop sci.30: 781-785.

[22]Zhang, F., Yang, Y.L., He, W.L., Zhao, X., Zhang, L.X. 2004. Effects of salinity on growth and compatible solutes of callus induced from Populus euphratica. In vitro Cell Dev. Biol., 40(5): 491-494. 